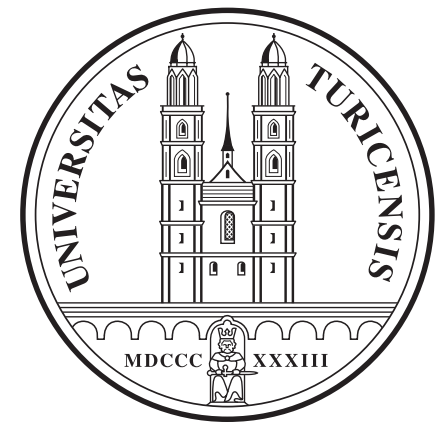

Institute for Empirical Research in Economics

University of Zurich

Working Paper Series

ISSN 1424-0459

Working Paper No. 30

Business Cycle Phenomena in Overlapping

Generations Economies with Stochastic Production

Jens-Ulrich Peter and Klaus Reiner Schenk-Hoppé

December 1999 


\title{
Business Cycle Phenomena in Overlapping Generations Economies with Stochastic Production
}

\author{
Jens-Ulrich Peter \\ Department of Economics \\ University of Bielefeld, Germany \\ jupeter@wiwi.uni-bielefeld.de
}

\author{
Klaus Reiner Schenk-Hoppé * \\ Institute for Empirical Research in Economics \\ University of Zurich, Switzerland \\ klaus@iew.unizh.ch
}

December $15,1999^{\dagger}$

\begin{abstract}
This paper analyzes economic fluctuations in an overlapping generations economy with productive capital in which random shocks in aggregate productivity are present. Under specific assumptions we obtain an explicit solution of the model. Applying random dynamical systems theory, we can prove that the long-run behavior of the economy is uniquely described by an asymptotically stable random fixed point. The statistical properties of the aggregates output, consumption, capital stock, and real wage are investigated numerically. We find that our artificial economy displays several real world business cycle phenomena.
\end{abstract}

Keywords: overlapping generations, real business cycles, technology shocks, random dynamical systems, random fixed points. JEL-Classification: E32, E37, E21, C62, D91

\section{Introduction}

A major focus of attention in the macroeconomic literature in the last decades has been the identification and explanation of the forces that cause business cycle phenomena, which are, as Prescott (1986, p. 9) puts it, "[...] nothing more nor less than a certain set of statistical properties of a certain set of important aggregate time series." More than 60 years ago Frisch (1933) proposed to distinguish between the impulse, i.e. the source of economic fluctuations, and the propagation mechanism of the impulse which leads to observable oscillations of economic aggregates. This point of view is particularly useful to explain the novelty of our

\footnotetext{
${ }^{*}$ Corresponding author.

${ }^{\dagger}$ Financial support by the Deutsche Forschungsgemeinschaft under contract BO 635/9-1 and the Institute for Empirical Research in Economics, University of Zurich, is gratefully acknowledged.
} 
approach to the investigation of the effects of technology shocks on economic aggregates and to point out similarities with the work attributable to the real business cycle school.

Real business cycle theory, as summarized in Frontiers of Business Cycle Research edited by Cooley (1995), builds on the assumption that the impulse is an exogenous technology shock (causing random fluctuations in aggregate productivity). The propagation mechanism has two components: the law of motion of the neoclassical stochastic growth model and the optimizing behavior of an infinitely lived representative agent. The transformation of supply-side shocks to fluctuations of the relevant economic aggregates (such as output, investment, consumption, employment, etc.) therefore originates from the response of rational individuals to the altered structure of their economic environment, which results in a permanent adjustment of demand and supply decisions. A major drawback of real business cycle models is the fact that in general they are not explicitly solvable. One therefore typically resorts to an analysis of a linear approximation around the deterministic steady state. Although this method is widely used in modern macroeconomics, see e.g. Taylor \& Uhlig (1990) and Marimon \& Scott (1999), it has to be applied with caution because its validity has not yet been established rigorously.

In the approach pursued here, we consider a stochastic version of the Diamond (1965) overlapping generations economy. While retaining the assumption that the impulse is a technology shock, we consider a different propagation mechanism. The optimizing behavior of an infinitely lived representative agent is replaced by an infinite sequence of young generations making optimal decisions. The law of motion of the stochastic growth model, however, is kept. From this point of view, the only difference in our model is the structure of the optimization problem of the individuals. It has several advantages to place our study within the framework of an overlapping generations economy with stochastic production. First, we can derive an explicit solution under less restrictive assumptions than in the standard real business cycle model and therefore are in a position to investigate the qualitative and quantitative dynamics of the original system. In particular we can avoid linearization of the underlying system. Second, due to the sequential structure of our model we can employ the theory of random dynamical systems which offers a mathematical framework for the description of economic models very much in the spirit of Frisch.

The availability of an explicit solution of the underlying stochastic system enables us to carry out a more detailed analysis than can be done by applying the concept of ergodic Markov equilibria. Employing the alternative concept of a random fixed point, which also provides a stochastic analogue of a deterministic fixed point, we can prove sample path stability of the time series of the main economic aggregates. This ensures the independence of the long-run behavior from the initial value. A detailed treatment of the random fixed point concept and an application to the Solow-Swan growth model is given by Schenk-Hoppé \& Schmalfuß (1998).

Existence and stability of ergodic Markov equilibria in a related overlapping generations model with i.i.d. and correlated production shocks has been investigated by Wang (1993, 1994). The same issues have been analyzed within Samuelson's pure exchange setting under uncertainty by Spear \& Srivastava (1986) among others.

In addition to a thorough analytical treatment, this paper provides a numerical examination of the statistical properties of certain time series deduced from our model. We compare our results with data from the U.S. economy, adopting the view of the real business cycles approach. We 
find that our artificial economy displays several real world business cycle phenomena. The simulations use publically available MATLAB ${ }^{\circledR}$ scripts, which facilitates the reproduction of our results.

The paper is organized in the following fashion. Section 2.1 introduces the general model. A detailed analysis of a particular case of the model is given in Section 2.2. A brief introduction to random dynamical systems theory is provided in Section 3.1. Section 3.2 presents the main analytical result of the paper on the existence of an asymptotically stable random fixed point. In Section 4 we provide a numerical study of the statistical properties and compare our findings with empirical data of the U.S. economy. Section 5 concludes, and the Appendix contains all proofs.

\section{The model}

\subsection{Basic elements of the economy}

Consider a Diamond (1965) overlapping generations economy with stochastic aggregate production. At any period of time, a single homogeneous good is produced which can be either consumed or used as capital input. Two factors, capital and labor, are needed in the production process, described by the linear homogeneous production function

$$
Y_{t}=F\left(K_{t}, L_{t}, z_{t}\right)=L_{t} f\left(k_{t}, z_{t}\right)
$$

where $K_{t}$ is the capital stock at the beginning of period $t, L_{t}$ is the exogenously given labor supply, $k_{t} \equiv K_{t} / L_{t}$ is the capital per worker ratio, and $z_{t}$ is a technological shock. For each possible realization of the exogenous variable $z_{t}$ the function $f\left(\cdot, z_{t}\right)$ is a neoclassical production function, i.e. $f\left(\cdot, z_{t}\right)$ is twice continuously differentiable and strictly concave on $\mathbb{R}_{+}$, and $f\left(0, z_{t}\right)=0$. The stochastic process governing the technology shock is a Markov process taking values $z_{t} \in \mathcal{Z} \equiv[\underline{z}, \bar{z}], 0<\underline{z} \leq \bar{z} \leq \infty$, with transition probability $P\left(z_{t}, B\right), B$ a Borel-subset of $\mathcal{Z}$.

Markets are perfectly competitive, capital and labor earn their marginal products in all states of nature, i.e.

$$
\begin{aligned}
r_{t} & =f_{1}\left(k_{t}, z_{t}\right) \\
w_{t} & =f\left(k_{t}, z_{t}\right)-k_{t} f_{1}\left(k_{t}, z_{t}\right)
\end{aligned}
$$

where $r_{t}$ and $w_{t}$ denote real interest rate and real wage, respectively. ${ }^{1}$

Population grows at a constant rate $n>-1$, i.e. $L_{t}=(1+n)^{t} L_{0}$ individuals are born in period $t, L_{0}>0$. Individuals are identical within as well as across time and live for two consecutive

\footnotetext{
${ }^{1}$ Throughout the paper integer subscripts of functions denote the partial derivative with respect to the corresponding argument, whereas letter subscripts denote the total derivative with respect to the corresponding variable.
} 
periods. Each young individual inelastically supplies one unit of labor and earns labor income $w_{t}$ which she divides between first-period consumption $c_{t}^{1}$ and saving $s_{t}$,

$$
c_{t}^{1}=w_{t}-s_{t} .
$$

In the second period of her life she retires and dissaves, i.e. she consumes the savings $s_{t}$ plus the accrued interest,

$$
c_{t+1}^{2}=\left(1-\delta+\tilde{r}_{t+1}\right) s_{t}
$$

where $\delta \in[0,1]$ is the rate of capital depreciation and $\tilde{r}_{t+1}$ denotes the next period's real interest rate. Futures markets are incomplete, i.e. $\tilde{r}_{t+1}$ is a random variable with realization in $\mathbb{R}_{+} \cdot^{2}$

We assume a closed economy, i.e. the endowment of capital per capita at the beginning of period $t+1$ is equal to the resources not consumed in the preceding period,

$$
k_{t+1}=\frac{f\left(k_{t}, z_{t}\right)+(1-\delta) k_{t}-c_{t}}{1+n}
$$

where $c_{t} \equiv c_{t}^{1}+c_{t}^{2} /(1+n)$ denotes total consumption per capita in period $t$.

The lifetime preferences of an individual born in period $t$ are described by a time-additive, state-dependent expected utility function ${ }^{3}$

$$
u\left(c_{t}^{1}\right)+\int_{\mathbb{R}_{+}} v\left(c_{t+1}^{2}, \tilde{r}_{t+1}\right) \mu\left(d \tilde{r}_{t+1}\right)
$$

where the functions $u(\cdot)$ and $v\left(\cdot, \tilde{r}_{t+1}\right.$ ) (for all $\tilde{r}_{t+1} \in \mathbb{R}_{+}$) are twice continuously differentiable, strictly increasing, strictly concave, and satisfy the Inada conditions. $\mu$ describes the subjective expectations concerning the distribution of the next period's real interest rate. ${ }^{4}$

The choices made during the first period are intended to maximize the lifetime utility function (6) subject to the budget constraints (3) and (4), i.e.

$$
s_{t}^{*}=\underset{0 \leq s_{t} \leq w_{t}}{\operatorname{argmax}}\left\{u\left(w_{t}-s_{t}\right)+\int_{\mathbb{R}_{+}} v\left(\left(1-\delta+\tilde{r}_{t+1}\right) s_{t}, \tilde{r}_{t+1}\right) \mu\left(d \tilde{r}_{t+1}\right)\right\}
$$

Under the above assumptions, the optimal saving decision $s_{t}^{*}$ is uniquely determined by the first-order condition

$$
u^{\prime}\left(w_{t}-s_{t}^{*}\right)=\int_{\mathbb{R}_{+}}\left(1-\delta+\tilde{r}_{t+1}\right) v_{1}\left(\left(1-\delta+\tilde{r}_{t+1}\right) s_{t}^{*}, \tilde{r}_{t+1}\right) \mu\left(d \tilde{r}_{t+1}\right)
$$

The saving function $s_{t}^{*}=s\left(w_{t}, \mu\right)$ depends only on the current total income $w_{t}$ and on the probability measure $\mu$.

We suppose in addition that the individual's saving decision is consistent with rational expectations.

\footnotetext{
${ }^{2}$ Note that wage and interest rate are normalized by the price of the consumption good in the respective period $t$. The young individual is uncertain about the future price of capital.

${ }^{3}$ The reader may consult e.g. Karni (1993a, 1993b) and Mas-Colell, Whinston \& Green (1995) for an extensive treatment of state-dependent expected utility theory.

${ }^{4}$ The dependence of second period utility on next period's real interest rate can be interpreted as a modeling of money illusion. Recent empirical studies by Shafir, Diamond \& Tversky (1997) and Fehr \& Tyran (1998) provide evidence that it matters in individual decision making whether a situation is represented in nominal or real terms.
} 
Definition 2.1 Let $\left(k_{t}, z_{t}\right) \in \mathbb{R}_{+} \times \mathcal{Z}$ be a current state of the economy. The saving behavior is called rational, if the subjective expectation $\mu \in \operatorname{Prob}\left(\mathbb{R}_{+}\right)$satisfies

$$
s\left(w_{t}, \mu\right)=s\left(w_{t}, f_{1}\left(\frac{s\left(w_{t}, \mu\right)}{1+n}, \cdot\right) P\left(z_{t}, \cdot\right)\right)
$$

where $w_{t}=w\left(k_{t}, z_{t}\right)$ is the real wage.

In general any probability measure $\mu$ which solves the functional equation (9) depends on the state of the economy. In Definition 2.1 it is required that the young individual makes her saving decision "as if" her subjective expectation $\mu$ coincides with the actual distribution of next period's real interest rate. ${ }^{5}$ If there exists a probability measure $\mu\left(w_{t}, z_{t}\right)$ for all $\left(k_{t}, z_{t}\right) \in \mathbb{R}_{+} \times \mathcal{Z}$, then the individual's saving behavior is rational along each sample path of the capital intensity $k_{t+1}=s\left(w\left(k_{t}, z_{t}\right), \mu\left(w\left(k_{t}, z_{t}\right), z_{t}\right)\right) /(1+n) .{ }^{6}$ The sequence of random variables $k_{t+1}$ together with $\mu\left(w\left(k_{t}, z_{t}\right), z_{t}\right)$ satisfying $(9)$ is also called a rational expectations equilibrium, cf. Grandmont (1977, Sec. 5.2).

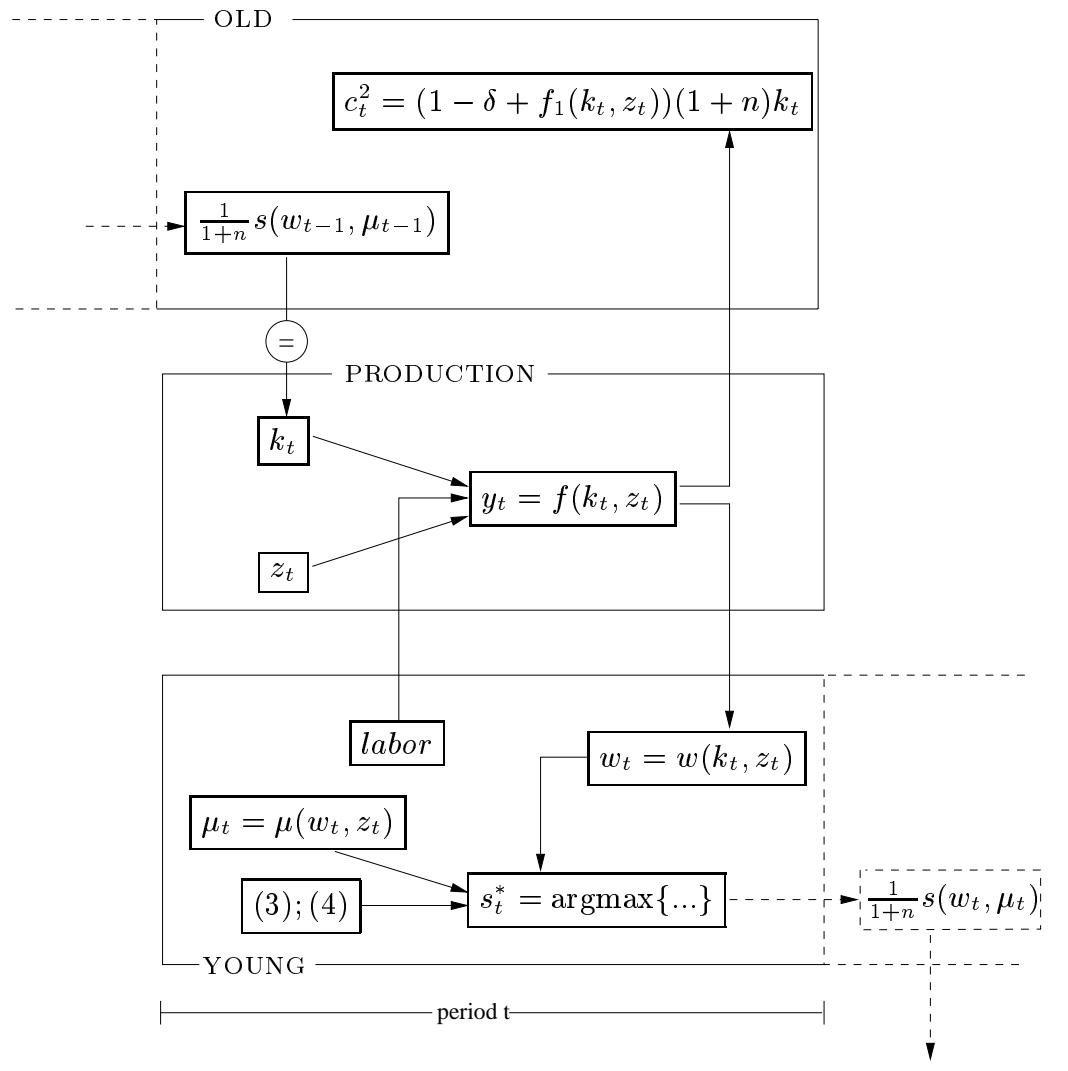

Figure 1: Illustration of the time structure of the overlapping generations economy with stochastic production.

\footnotetext{
${ }^{5}$ The condition $\mu=f_{1}\left(s\left(w_{t}, \mu\right) /(1+n), \cdot\right) P\left(z_{t}, \cdot\right)$ is sufficient (but not necessary) for rational saving behavior in the sense of Definition 2.1.

${ }^{6}$ Any non-rational saving behavior leads to a sample path of real interest rates which shows that the saving decisions have not been optimal given the observed distribution of real interest rates.
} 
Suppose there exists a solution $\mu\left(w_{t}, z_{t}\right)$ of the functional equation (9) for all $\left(k_{t}, z_{t}\right) \in \mathbb{R}_{+} \times \mathcal{Z}$. Then we have a complete specification of an overlapping generations economy with stochastic production and rational expectations. In particular the time structure of the economy at issue is depicted in Figure 1. It can be summarized as follows. The material balance equation (5) implies that at the beginning of period $t$ the savings $s_{t-1}^{*}$ of the generation born in period $t-1$ leads to the current beginning-of-period capital intensity $k_{t}=s_{t-1}^{*} /(1+n)$. In combination with the one unit of labor supplied inelastically by the current young generation and the current realization of the shock, the per capita output is $f\left(k_{t}, z_{t}\right)$. The latter is shared between the net return to the capital owners, $\left(1-\delta+f_{1}\left(k_{t}, z_{t}\right)\right) s_{t-1}^{*}$, which they consume immediately, and the labor income, $w_{t}$, of the current young generation. Based on the probability distribution $\mu$ the young solve (8) to determine their savings $s_{t}^{*}=s\left(w_{t}, \mu\left(w_{t}, z_{t}\right)\right)$.

\subsection{Assumptions on technology and preferences}

Conditions characterizing the optimal saving decision and the rational expectations equilibrium were given in the previous section. In order to obtain an explicit law of motion for the capital stock, we have to restrict the further treatment to particular utility and production functions.

Assumption 2.1 The production process is described by the per capita production function

$$
f\left(k_{t}, z_{t}\right)=A z_{t} \log \left(1+k_{t}\right), \quad A>1 .
$$

The lifetime preferences of an individual born in period t are described by the state-dependent expected utility function

$$
u\left(c_{t}^{1}\right)+\int_{\mathbb{R}_{+}} v\left(c_{t+1}^{2}, \tilde{r}_{t+1}\right) \mu\left(d \tilde{r}_{t+1}\right)=\log c_{t}^{1}+\int_{\mathbb{R}_{+}}\left(1-\delta+\tilde{r}_{t+1}\right) \log c_{t+1}^{2} \mu\left(d \tilde{r}_{t+1}\right) .
$$

For each possible realization of the exogenous shock the production function is neoclassical and has diminishing returns. A denotes the level of technology. The lifetime utility function satisfies all assumptions made in Section 2.1.

With these specifications of preferences and technology, the marginal products of capital and labor are given by

$$
\begin{aligned}
r_{t} & =\frac{A z_{t}}{1+k_{t}} \\
w_{t} & =A z_{t}\left(\log \left(1+k_{t}\right)-\frac{k_{t}}{1+k_{t}}\right)
\end{aligned}
$$

and the first-order condition (8) becomes

$$
\frac{s_{t}^{*}}{w_{t}-s_{t}^{*}}=1-\delta+\int_{\mathbb{R}_{+}} \tilde{r}_{t+1} \mu\left(d \tilde{r}_{t+1}\right) .
$$


The saving function is therefore of the form

$$
s_{t}^{*}=s\left(w_{t}, R^{\mu}\right)=\frac{R^{\mu}}{1+R^{\mu}} w_{t}
$$

and depends only on the current total income $w_{t}$, and on $R^{\mu} \equiv 1-\delta+\mathbb{E}^{\mu} \tilde{r}_{t+1}$, the subjective mean of the real net return on next period's capital.

Thus, given the current state of the economy $\left(k_{t}, z_{t}\right)$, the saving behavior described by the function $s\left(w\left(k_{t}, z_{t}\right), R^{\mu}\right)$ is rational if the subjective probability distribution $\mu$ satisfies

$$
R^{\mu}=1-\delta+\mathbb{E}^{P\left(z_{t}, \cdot\right)}\left(\frac{(1+n) A z_{t+1}}{1+n+s\left(w\left(k_{t}, z_{t}\right), R^{\mu}\right)}\right)
$$

where $w\left(k_{t}, z_{t}\right)$ is the real wage function (13).

Elementary calculations yield the following result.

Lemma 2.1 The saving behavior of the young is rational if and only if

$$
R^{\mu}=R\left(w_{t}, z_{t}\right)=\frac{-b\left(w_{t}, z_{t}\right)+\sqrt{b\left(w_{t}, z_{t}\right)^{2}+4 a\left(w_{t}\right) c\left(z_{t}\right)}}{2 a\left(w_{t}\right)}
$$

where $a\left(w_{t}\right) \equiv 1+n+w_{t}, b\left(w_{t}, z_{t}\right) \equiv(1+n)\left(1-A \mathbb{E}\left(z_{t+1} \mid z_{t}\right)\right)-(1-\delta) a\left(w_{t}\right), c\left(z_{t}\right) \equiv$ $(1+n)\left(A \mathbb{E}\left(z_{t+1} \mid z_{t}\right)+1-\delta\right), \mathbb{E}\left(z_{t+1} \mid z_{t}\right) \equiv \int_{\mathcal{Z}} z_{t+1} P\left(z_{t}, d z_{t+1}\right)$, and $w_{t} \equiv w\left(k_{t}, z_{t}\right)$.

We will refer to $R\left(w_{t}, z_{t}\right)$ as the mean-return-on-capital function. Lemma 2.1 implies that the law of motion for the capital intensity is described by the random difference equation

$$
k_{t+1}=h\left(k_{t}, z_{t}\right) \equiv \frac{s\left(w\left(k_{t}, z_{t}\right), R\left(w\left(k_{t}, z_{t}\right), z_{t}\right)\right)}{1+n}=\frac{R\left(w\left(k_{t}, z_{t}\right), z_{t}\right)}{1+R\left(w\left(k_{t}, z_{t}\right), z_{t}\right)} \frac{w\left(k_{t}, z_{t}\right)}{1+n}
$$

Having this law of motion at hand, one could carry out numerical simulations and determine the statistical properties of the economic aggregates. Note that the dynamics of the actual system can be analyzed, because no approximations were necessary to derive (17). However, our aim in this paper is to first provide a complete analytical description of long-run dynamics of (17). After having ensured convergence of all sample paths of the capital intensity, we present a numerical study of the statistical behavior for appropriate parameter values. In order to achieve this goal and to keep the problem analytically tractable, we impose the following standard assumptions on the parameters.

Assumption 2.2 No population growth, i.e. $n=0$; capital depreciates fully after one period, i.e. $\delta=1$; and the technology shock is i.i.d. and has unity mean, i.e. $\mathbb{E}\left(z_{t+1} \mid z_{t}\right)=1$. 

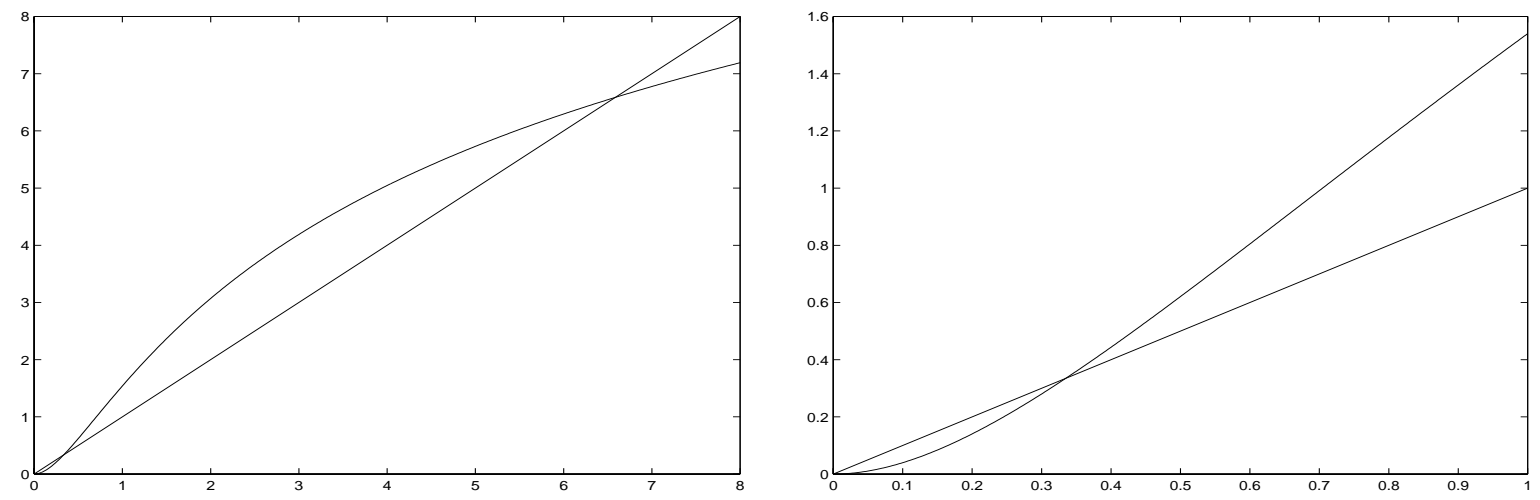

Figure 2: Deterministic law of motion corresponding to (19), i.e. $z_{t} \equiv 1$, with $A=10$. On the left $h(k, 1)$ is depicted as a function of the capital stock $k$. The right figure is an enlargement for small capital stocks. The graph of the identity map is shown for reference.

With this specification of the exogenous variables the mean-return-on-capital function of Lemma 2.1 reduces to

$$
R\left(w_{t}\right)=\frac{A-1+\sqrt{(A+1)^{2}+4 A w_{t}}}{2\left(1+w_{t}\right)}
$$

which is in particular independent of $z_{t}$. The law of motion for the capital stock is therefore given by

$$
k_{t+1}=h\left(k_{t}, z_{t}\right) \equiv\left[1+\frac{2\left(1+w\left(k_{t}, z_{t}\right)\right)}{A-1+\sqrt{(A+1)^{2}+4 A w\left(k_{t}, z_{t}\right)}}\right]^{-1} w\left(k_{t}, z_{t}\right)
$$

where $w\left(k_{t}, z_{t}\right)$ is determined by $(13)$.

Let us briefly describe the dynamical behavior of the deterministic system associated to (19) $k_{t+1}=h\left(k_{t}, 1\right)$ with level of technology $A=10$. Figure 2 shows that $h(k, 1)$ is S-shaped and intersects the graph of the identity map at zero, $k_{u} \approx 0.3347$, and $k_{s} \approx 6.5853$. The points zero and $k_{s}$ are asymptotically stable and the point $k_{u}$ is unstable. All initial capital stocks in $\left[0, k_{u}\right.$ [ converge toward 0 , and all initial capital stocks in $] k_{u}, \infty\left[\right.$ converge toward $k_{s}$. The non-trivial stable steady state is therefore observed in the long-run for all sufficiently large initial capital stocks while zero is a poverty trap.

Under Assumption 2.1 we can prove several properties of the functions determining real wage and saving and of the law of motion of the capital stock. They are collected below.

Lemma 2.2 For each possible realization of the technology shock $z$, the real wage function $w(k, z)$ has the following properties

a) $w(0, z)=0$, and $w(1, z) \geq 1$ if and only if $A \geq 1 /(z \beta)$, where $\beta \equiv \log 2-1 / 2$;

b) $w(\cdot, z)$ is strictly increasing, $w_{1}(0, z)=0$, and $\lim _{k \rightarrow \infty} w_{1}(k, z)=0$; 
c) $w(\cdot, z)$ is $S$-shaped with (unique) inflection point at $k=1$.

Lemma 2.3 The saving function $s(w, R(w))=\frac{R(w)}{1+R(w)} w$ has the following properties

a) $s(0, R(0))=0$;

b) $s(\cdot, R(\cdot))$ is strictly increasing with $s_{w}(0, R(0))=A /(A+1)<1$;

c) $s(\cdot, R(\cdot))$ is strictly concave.

Lemma 2.4 The law of motion $h(k, z)$ has the following properties

a) $h(0, z)=0$;

b) $h(1, z) \geq 1$ if $A \geq\left(1+z \beta+\sqrt{(1+z \beta)^{2}+4 z \beta}\right) /(2 z \beta)$, where $\beta \equiv \log 2-1 / 2$;

c) $h(k, \cdot)$ and $h(\cdot, z)$ are strictly increasing, and $h_{1}(0, z)=0$;

d) $h(\cdot, z)$ is strictly concave for all $k \geq 1$.

Lemma 2.5 Suppose that

$$
A \geq\left(1+\underline{z} \beta+\sqrt{(1+\underline{z} \beta)^{2}+4 \underline{z} \beta}\right) /(2 \underline{z} \beta)
$$

where $\beta \equiv \log 2-1 / 2$. Then, for each fixed technology shock $z \in[\underline{z}, \bar{z}]$, the law of motion $h(k, z)$ possesses a maximal fixed point $k(z)$. Moreover, $k(z) \geq 1$ and $k(z)$ is increasing in $z$.

\section{Analytical results}

Our analytical study of the dynamical behavior of the capital stock -described by the stochastic law of motion (19) - will be placed within the framework of random dynamical systems. We briefly sketch this framework here and refer the reader to the monograph by Arnold (1998) for additional information. The characterization of the long-run behavior uses the concept of a random fixed point. Existence of a non-trivial asymptotically stable random fixed point of (19) will be proved by applying a random version of the Banach fixed point theorem due to Schmalfuß (1996, 1998), see also Schenk-Hoppé \& Schmalfuß (1998). 


\subsection{The mathematical framework}

A random dynamical system provides a mathematical description of dynamical systems that are subject to random perturbations. It consists of two ingredients: a model of the perturbation (here an ergodic dynamical system) and a model of the system perturbed by noise (here an invertible smooth mapping on $\mathbb{R}_{+}$).

Let $(\Omega, \mathcal{F}, \mathbb{P})$ denote a probability space, and let $\theta: \Omega \rightarrow \Omega$ be a measurable invertible mapping with measurable inverse $\theta^{-1}$ such that $\mathbb{P}$ is ergodic with respect to $\theta$. Finally, let $z: \Omega \rightarrow \mathcal{Z}$ be a measurable function. Then for each fixed $\omega \in \Omega, z\left(\theta^{t} \omega\right)$ with $t \in \mathbb{Z}$, is a sample path of the random perturbation. It is well-known that any real-valued ergodic process possesses such a representation, cf. Arnold (1998, Appendix A). In particular, if the production shock $z_{t}$ is any sequence of $\mathcal{Z}$-valued i.i.d. random variables with distribution $\nu$, then $(\Omega, \mathcal{F}, \mathbb{P})=\left(\mathcal{Z}^{\mathbb{Z}}, \mathcal{B}(\mathcal{Z})^{\mathbb{Z}}, \nu^{\mathbb{Z}}\right)$ with $\Omega$ being the space of sample paths of $z_{t}$, i.e. each element of $\Omega$ is a two-sided infinite sequence. $\theta: \Omega \rightarrow \Omega, \theta^{t}(\omega(\cdot)) \equiv \omega(t+\cdot)$ denotes the left-shift on $\Omega$, and $z: \Omega \rightarrow \mathcal{Z}, z(\omega) \equiv \omega(0)$ denotes the evaluation map. $\mathbb{P}$ is ergodic with respect to $\theta$. The technology shock is therefore described by the stochastic process $z\left(\theta^{t} \omega\right), t \in \mathbb{Z}$.

Denote by $\varphi(t, \omega, k)$ the state of the stochastic system (19) at time $t$ with initial state $k$ under the realization of the production shocks $\left(z\left(\theta^{*} \omega\right)\right)$ up to time $t$ which is determined by $\omega$. Then one has that

$$
\varphi(t, \omega, k)= \begin{cases}h\left(\cdot, z\left(\theta^{t-1} \omega\right)\right) \circ \ldots \circ h(k, z(\omega)) & \text { for all } t \geq 1 \\ k & \text { for } t=0 \\ h\left(\cdot, z\left(\theta^{t} \omega\right)\right)^{-1} \circ \ldots \circ h\left(k, z\left(\theta^{-1} \omega\right)\right)^{-1} & \text { for all } t \leq-1\end{cases}
$$

and, in particular, $\varphi(1, \omega, \cdot) \equiv h(\cdot, z(\omega))$.

The family of maps $\varphi(t, \omega, k)$ is called the random dynamical system generated by (19). That is, $\varphi: \mathbb{Z} \times \Omega \times \mathbb{R}_{+} \rightarrow \mathbb{R}_{+},(t, \omega, k) \mapsto \varphi(t, \omega, k) \equiv \varphi(t, \omega) k$ is a measurable map such that $\varphi(0, \omega)=\operatorname{id}_{\mathbb{R}_{+}}$and $\varphi(s+t, \omega)=\varphi\left(t, \theta^{s} \omega\right) \circ \varphi(s, \omega)$ for all $s, t \in \mathbb{Z}$ and for all $\omega \in \Omega$. These properties replace the flow property of a deterministic dynamical system generated by a map.

Definition 3.1 A random fixed point of the random dynamical system $\varphi$ generated by $h$ is a random variable $k^{\star}: \Omega \rightarrow \mathbb{R}_{+}$such that almost surely

$$
k^{\star}(\theta \omega)=\varphi\left(1, \omega, k^{\star}(\omega)\right) \equiv h\left(k^{\star}(\omega), z(\omega)\right) .
$$

The random fixed point $k^{\star}$ is called asymptotically stable if there exists a (random) neighborhood of $k^{\star}(\omega)$ for almost all $\omega$ such that for all $k$ in this neighborhood $\lim _{t \rightarrow \infty} \mid \varphi(t, \omega, k)-$ $k^{\star}\left(\theta^{t} \omega\right) \mid=0$.

In the absence of the perturbation (22) reduces to the definition of a fixed point of a map. Equation (22) implies that $k^{\star}\left(\theta^{t} \omega\right)=\varphi\left(t, \omega, k^{\star}(\omega)\right)$ for all $t \in \mathbb{Z}$. 


\subsection{Long-run behavior}

The qualitative dynamics of the deterministic law of motion associated to (19) has been sketched at the end of Section 2.2. We present here a result on the long-run behavior of the capital stock in the general stochastic case. Throughout the following we impose all assumptions made in Section 2.2.

Theorem 3.1 (i) Zero is an asymptotically stable fixed point for the random dynamical system associated to (19), i.e. for all sufficiently small initial capital stocks the state of the economy converges to the zero-capital state (and therefore zero is a poverty trap). If $\mathcal{Z}$ is bounded then there exists a deterministic neighborhood of zero which is attracted by zero.

(ii) Suppose condition (20) holds and

$$
\mathbb{E} \log h_{1}(k(\underline{z}), z(\omega))<0
$$

where $k(\underline{z})$ denotes the maximal fixed point of the map $k \mapsto h(k, \underline{z})$, see Lemma 2.5.

Then there exists a unique random fixed point $k^{\star}(\omega) \in[k(\underline{z}), \infty[$ which is asymptotically stable and attracting on $[k(\underline{z}), \infty[$, i.e. for all initial capital stocks in $[k(\underline{z}), \infty[$, the capital stock of the economy following the law of motion (19) converges to the sample path $t \mapsto k^{\star}\left(\theta^{t} \omega\right)$.

By minor additional expenses one can show that the random fixed point $k^{\star}$ is even attracting on $[1, \infty[$ : Lemma 2.5 yields that $h(z, 1)>h(\underline{z}, 1) \geq 1$ for all $z>\underline{z}$. Hence for any nondegenerated process of technology shocks, a finite number of realizations $z(\theta \omega)>\underline{z}$ will lead to a capital stock $\varphi(t, \omega, 1) \geq k(\underline{z})$. Now the above attraction property gives the result. In the next section we make use of this observation and choose $k=2$ as the initial capital stock in the numerical simulations.

A direct consequence of Theorem 3.1 is that the economic aggregates output, consumption, and real wage also converge to the sample path of a random fixed point. For instance the random fixed points for output and real wage are given by $y^{\star}(\omega) \equiv f\left(k^{\star}(\omega), z(\omega)\right)=A z(\omega) \log (1+$ $\left.k^{\star}(\omega)\right)$ and $w^{\star}(\omega) \equiv A z(\omega)\left(\log \left(1+k^{\star}(\omega)\right)-k^{\star}(\omega) /\left(1+k^{\star}(\omega)\right)\right)$, respectively.

The proof of Theorem 3.1(ii) shows that random fixed point $k^{\star}(\omega)$ is measurable with respect to the past, $\sigma\left\{\omega \mapsto z\left(\theta^{t} \omega\right) \mid t \leq 0\right\} . \quad\left(k^{\star}(\omega)\right.$ is in particular the limit of any deterministic initial value being larger than $k(\underline{z})$.) Since the technology shocks are i.i.d., this $\sigma$-algebra is independent of the future, $\sigma\left\{\omega \mapsto z\left(\theta^{t} \omega\right) \mid t>0\right\}$. By Schenk-Hoppé \& Schmalfuß (1998, Proposition A.2) we have the following result.

Corollary 3.1 Under the assumptions made in Theorem 3.1(ii) there exists a unique ergodic Markov equilibrium on $\left[k(\underline{z}), \infty\left[\right.\right.$. It is given by $\rho \equiv k^{\star} \mathbb{P}$, i.e. $\rho(B)=\mathbb{P}\left\{k^{\star}(\omega) \in B\right\}$ for all Borel-sets $B \subset \mathbb{R}_{+}$.

We may readily conclude that Theorem 3.1 provides more detailed information on the dynamics of (19) than can be obtained from the existence of a ergodic Markov equilibrium.

Restricting Theorem 3.1 to the deterministic case $z(\omega) \equiv 1$ yields an existence result for a non-trivial asymptotically stable fixed point. This has already been observed numerically in Section 2.2. The following result shows that such a situation is preserved under small technology shocks. 
Corollary 3.2 Assume that $A>\left(1+\beta+\sqrt{(1+\beta)^{2}+4 \beta}\right) /(2 \beta)$. Then there exists a proper interval $[\underline{z}, \bar{z}]=\mathcal{Z} \ni 1$ such that the assumptions of Theorem 3.1(ii) are satisfied for all i.i.d. processes of technology shocks with values in $\mathcal{Z}$ and $\mathbb{E} z(\omega) \equiv 1$.

\section{Numerical analysis}

The rapidly expanding strand of literature on business cycles has provoked considerable controversy during the last decades on the ability of macroeconomic models to explain the empirically observed regularities of economic fluctuations. The central issue of the real business cycle research program is to construct suitable artificial economies which exhibit the observable stylized facts of business cycles. Its proponents Hansen (1985), Prescott (1986), King, Plosser \& Rebelo (1988), and McCallum (1989) among others have achieved remarkable results in that the constructed model is able to mimic the fluctuations of some relevant economic aggregates of actual economies.

Employing the analytical results on the long-run dynamics of our artificial economy, we present a numerical study of the statistical properties of some time series deduced from our model. We emphasize that our selection of the stylized facts is only guided by the structure of the overlapping generations model with stochastic production. The economic aggregates at issue are output, consumption, capital stock, and real wage.

Using established statistics of the U.S. economy since the Korean War, we compare volatilities, volatilities relative to output, and correlations of our time series with these empirical data. In doing so, we partly adopt the view of the real business cycles approach. The achieved numerical evidence suggests that our model can account for several stylized facts of business cycles. However, we have to point out that our analysis abstracts from any sort of calibration.

Parameter values in our experiments are chosen such that our analytical results ensure that for each initial capital intensity $k \geq 1$ the path of capital stocks $t \mapsto \varphi(t, \omega, k)$ converges toward the sample path $k^{\star}\left(\theta^{t} \omega\right)$ of the random fixed point $k^{\star}$. As pointed out previously, output, consumption, and real wage also converge toward the sample path of a corresponding random fixed point. We fix the parameter values in our two experiments as follows: the level of technology $A=10$ is fixed throughout the following and the productivity shock $z(\omega)$ is uniformly distributed on the intervals $[0.9985,1.0015]$ and $[0.85,1.15]$, respectively. Numerical simulations show that the right-hand side of the parameter constraint (20) is roughly equal to 6.93 for $\underline{z}=0.9985$ and roughly equal to 7.87 for $\underline{z}=0.85$. Therefore $A=10$ satisfies (20) in both cases. Furthermore, the contraction condition (23) is fulfilled because numerical tests yield $\mathbb{E} \log h_{1}(k(0.9985), z(\omega)) \approx-0.734<0$ and $\mathbb{E} \log h_{1}(k(0.85), z(\omega)) \approx-0.648<0$, respectively. In summary, we find that Theorem 3.1(ii) applies for the chosen parameter values.

The software MATLAB ${ }^{\circledR} 5.3$ is used in all simulations. The MATLAB ${ }^{\circledR}$ scripts developed for our study are publically available at the web page Schenk-Hoppé (1999). We encourage the interested reader to check our results.

In order to illustrate the results of Section 3.2, Figure 3 (top) depicts sample paths of the capital stock $\varphi(t, \omega, k)$ for different initial values $k$, fixed $\omega$, and $t=0, \ldots, 30$ with $\mathcal{Z}=[0.85,1.15]$. 

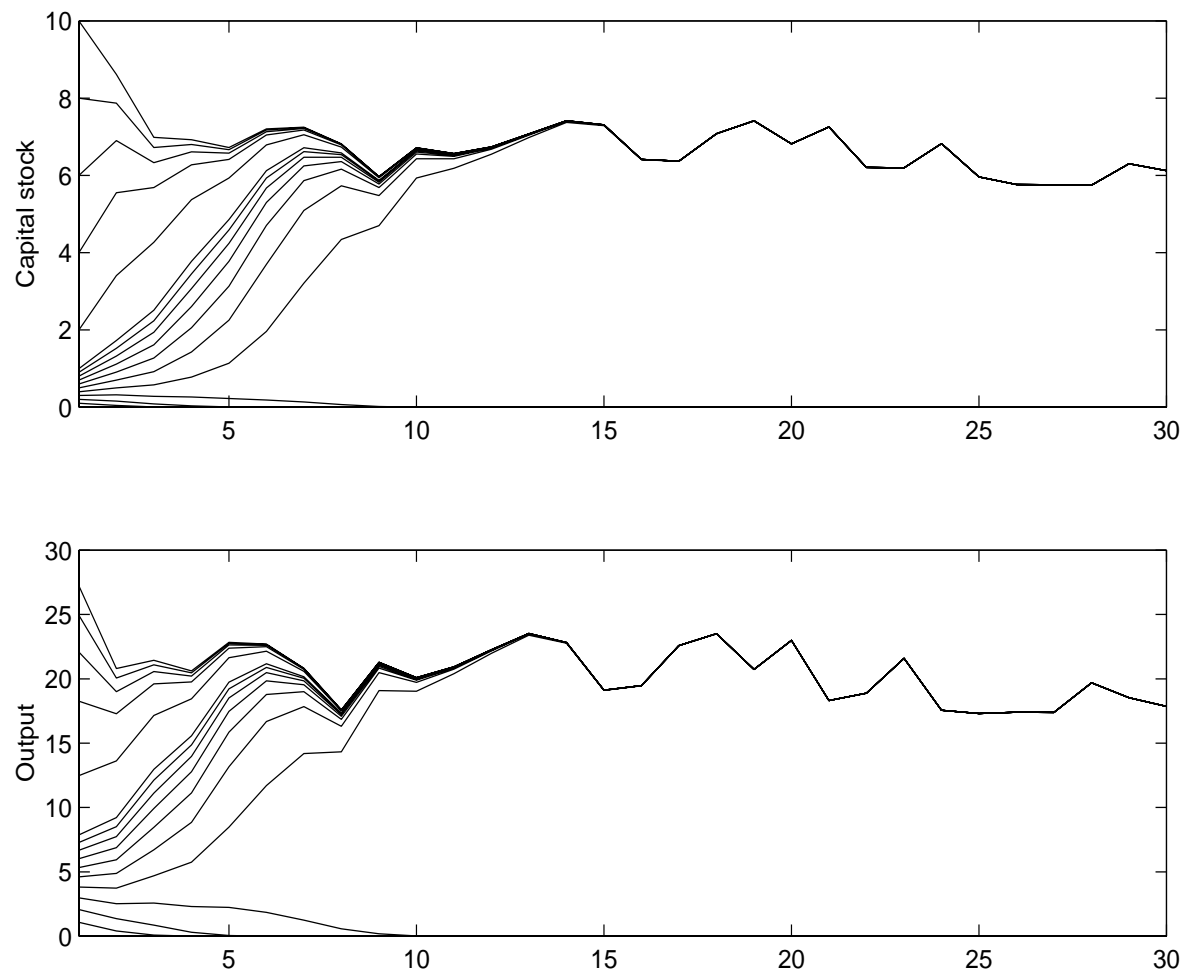

Figure 3: Evolution of capital stock (top) and output (bottom) for different initial capital stocks and the same sequence of technology shocks. $A=10$, $\mathcal{Z}=[0.85,1.15]$.

The corresponding per capita output is shown in Figure 3 (bottom). It can be observed that the sample paths of all sufficiently large initial capital stocks converge quickly to the path $k^{\star}\left(\theta^{t} \omega\right)$ of the random fixed point. For small initial capital stocks the sample paths converge toward the steady state of zero capital. The output has the same dynamical behavior as the capital stock.

Next, we turn to the statistical part of our numerical analysis. The convergence property together with the ergodic theorem ensures that all quantities calculated below can be approximated by averaging along corresponding sample paths. For instance, for any $k \geq 1$ one has $\mathbb{E} k^{\star}=\lim _{T \rightarrow \infty} 1 / T \sum_{t=0}^{T} \varphi(t, \omega, k)$ almost surely. The statistical properties of the time series for the artificial economies studied here are summarized in Tables 1, 2, and 3. The standard deviations and correlations reported with output are generated as follows. First, $k=2$ is taken as the initial capital intensity and 1,000 iterations of (19) are carried out to ensure that the capital stock is sufficiently close to the sample path of the random fixed point. Second, 40, 000 iterations are done to calculate the standard deviations and correlations of all variables.

The statistics for the U.S. economy, which are adopted from Hansen (1985), Danthine \& Donaldson (1993), and Kydland \& Prescott (1990), are reported in the first three columns of Table 1 and Table 2, respectively.

We take these data as the summary benchmark of basic business cycle stylized facts which serves as the empirical foundation in most real business cycle studies, cf. Danthine \& Donaldson 
(1993). Their qualitative interpretation is as follows: output is more volatile than the other aggregates, and the variability of consumption is about the same as that of the real wage and more pronounced than the variability of the capital stock. All of these variables are procyclical, but the correlation of the capital stock with output is comparably small.

\begin{tabular}{|c|c|c|c|c|c|c|c|c|c|}
\hline & \multicolumn{3}{|c|}{$\begin{array}{l}\text { U.S. economy } \\
(1955-1984)\end{array}$} & \multicolumn{3}{|c|}{$\begin{array}{l}\text { Artificial economy } \\
\mathcal{Z}=[0.9985,1.0015]\end{array}$} & \multicolumn{3}{|c|}{$\begin{array}{c}\text { Artificial economy } \\
\mathcal{Z}=[0.85,1.15]\end{array}$} \\
\hline Variable & s.d.(\%) & r.s.d. & corr. & s.d.(\%) & r.s.d. & corr. & s.d. & r.s.d. & corr \\
\hline Output & 1.76 & 1.00 & 1.00 & 1.87 & 1.00 & 1.00 & 1.86 & 1.00 & 1.00 \\
\hline Consumption & 1.29 & 0.73 & 0.85 & 1.41 & 0.75 & 0.99 & 1.39 & 0.75 & 0.99 \\
\hline Capital stock & 0.63 & 0.36 & 0.04 & 0.48 & 0.25 & 0.34 & 0.47 & 0.25 & 0.33 \\
\hline Real wage & 1.18 & 0.67 & 0.42 & 1.15 & 0.61 & 0.98 & 1.13 & 0.61 & 0.98 \\
\hline
\end{tabular}

Table 1: Source for U.S. data: Hansen (1985) and Danthine \& Donaldson (1993). Artificial economy data simulated by Schenk-Hoppé (1999). s.d. = standard deviation, r.s.d. $=$ s.d. relative to output, corr. $=$ correlation with output.

Consider first the results of our numerical experiments for small technology shocks, i.e. $\mathcal{Z}=$ $[0.9985,1.0015]$. These are listed in the second three columns of Table 1 and the first four columns of Table 3 . The numerical data display the benchmark business cycle facts reasonably well. The standard deviations of the aggregates output, consumption, capital stock, and real wage are about the same as those of the actual economy. The standard deviations relative to output of consumption and real wage show high accordance with the empirical data. Only the capital stock is less volatile in relative terms than the actual data predict. The correlations of consumption, capital stock, and real wage with output only exhibit the same qualitative behavior: consumption and real wage correlate much stronger with output than the capital stock with output.

\begin{tabular}{lccccc}
\multicolumn{6}{c}{ U.S. economy (1954-1989) } \\
\hline Variable & s.d.(\%) & $x(t-1)$ & $x(t)$ & $x(t+1)$ & $x(t+2)$ \\
\hline Output & 1.71 & 0.85 & 1.00 & 0.85 & 0.63 \\
Consumption & 1.25 & 0.81 & 0.82 & 0.66 & 0.45 \\
Capital stock & 0.62 & -0.31 & -0.08 & 0.16 & 0.39 \\
Real wage & 1.58 & 0.68 & 0.88 & 0.90 & 0.80 \\
\hline
\end{tabular}

Table 2: Cross correlations of output with different variables for the U.S. economy. Source: Kydland \& Prescott (1990), Table 1 and Table 2.

Concerning the cross correlations of output with other aggregates we have to concede that the degree of accordance between the values of our artificial economy and the values actually observed is rather weak. However, the cross correlations of output and consumption are tendencially decreasing in the length of the time lag. The cross correlations of the actual capital stock increases, while in our experiment they are largest for one period ahead, and 


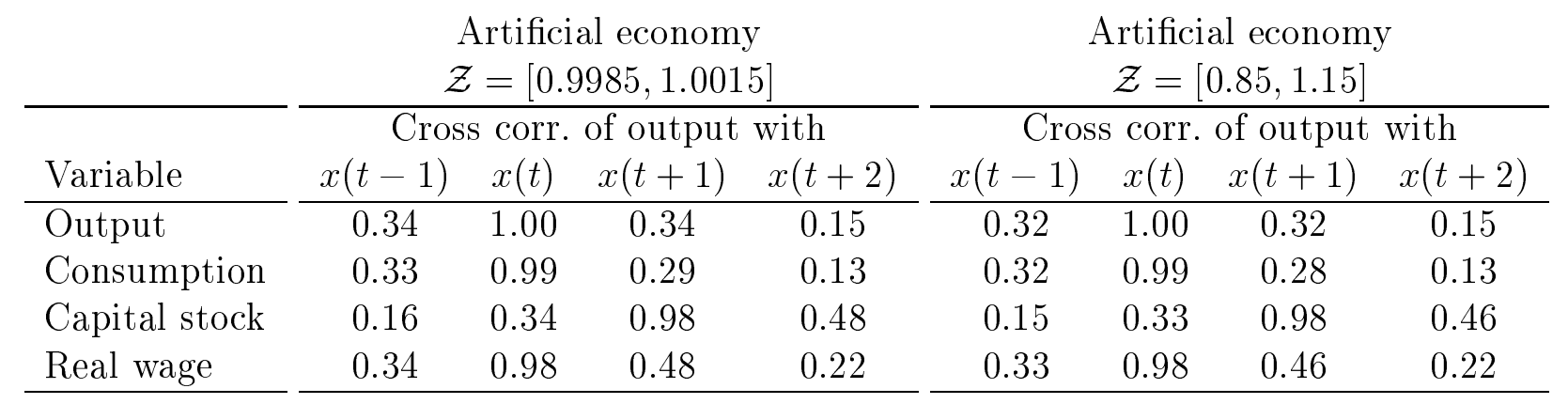

Table 3: Cross correlations of output with different variables for two artificial economies, Schenk-Hoppé (1999).

are otherwise decreasing. The cross correlation of real wage is in the actual as well as in the artificial economy maximal in the current period. We conjecture that the source of aberrations of the cross correlations is due to the structure of our overlapping generations model.

To test whether these observations depend crucially on the strength of the technology shocks, we compare our findings with the example in which $\mathcal{Z}=[0.85,1.15]$. The shocks have a 100 times larger maximal magnitude. The results are listed in the last three columns of Table 1 and the last four columns of Table 3. We find that the standard deviations relative to output and the correlations are almost unaltered. The volatility of the aggregates increases inevitably. The cross correlations display similar properties as in the small noise case. Summarizing we may conclude that the strength of the technology shock only affects the absolute volatility and that the relations measured in relative terms remain unaltered.

\section{Conclusions}

In this paper we examine business cycle phenomena in an overlapping generations economy in which random fluctuations in aggregate productivity are present. Crucial features of our model are a time-additive and state-dependent expected utility function and a logarithmic production function with multiplicative shocks. These assumptions guarantee the explicit solvability of the stochastic system. Employing the concept of a random fixed point, we can prove sample path stability of the time series of the main economic aggregates. Moreover, this paper presents a numerical investigation of the statistical properties of the economic aggregates output, consumption, capital stock, and real wage. We compare our findings with data from the U.S. economy. It turns out that our artificial economy displays several real world business cycle phenomena. 


\section{Appendix}

Proof of Lemma 2.1: Equation (15) is equivalent to $\frac{(1+n) A \mathbb{E}\left(z_{t+1} \mid z_{t}\right)}{1+n+s\left(w_{t}, R^{\mu}\right)}=R^{\mu}-(1-\delta)$. Together with (14) we obtain

$$
\begin{aligned}
\left(1+n+w_{t}\right)\left(R^{\mu}\right)^{2}+\left[(1+n)\left(1-A \mathbb{E}\left(z_{t+1} \mid z_{t}\right)\right)-(1-\delta)\left(1+n+w_{t}\right)\right] & R^{\mu} \\
& =(1+n)\left(A \mathbb{E}\left(z_{t+1} \mid z_{t}\right)+1-\delta\right) .
\end{aligned}
$$

Equation (16) is derived by solving this quadratic equation.

Proof of Lemma 2.2: Property a) is a simple consequence of the definition of the total income function. Differentiating $w(k, z)$ with respect to $k$ yields $w_{1}(k, z)=\frac{A z k}{(1+k)^{2}}$. Therefore, $w_{1}(k, z)=0$ if and only if $k=0$ or $k=\infty$, and $w_{1}(k, z)>0$ for all $k>0$. This is b). To prove $\mathrm{c}$ ) we have to show that $k=1$ is the unique point such that $w_{11}(k, z)=0$ and $w_{11}(k, z)$ changes sign. This follows directly from the fact that $w_{11}(k, z)=(A z(1-k)) /(1+k)^{3}$.

Proof of Lemma 2.3: Property a) is a simple consequence from the definition of the saving function. Let us show b). The total derivative of $s$ with respect to $w$ is

$$
\begin{aligned}
s_{w}(w, R(w)) & =\frac{R(w)}{1+R(w)}+\frac{R_{w}(w)}{R(w)^{2}(1+R(w))^{2}} w \\
& =\frac{s(w, R(w))}{w}\left[1+s(w, R(w)) \frac{R_{w}(w)}{R(w)^{2}}\right]
\end{aligned}
$$

where $R(w)$ is given by $(18)$ and

$$
R_{w}(w)=\frac{A-R(w) \sqrt{(A+1)^{2}+4 A w}}{(1+w) \sqrt{(A+1)^{2}+4 A w}} .
$$

Since $R(0)=A$, it follows that $s_{w}(0, R(0))=A /(A+1)$. For all $w>0, s(w, R(w)) / w>0$ and

$$
\begin{aligned}
1 & +s(w, R(w)) \frac{R_{w}(w)}{R(w)^{2}}=1+\frac{w}{R(w)(1+R(w))} \frac{A-R(w) \sqrt{(A+1)^{2}+4 A w}}{(1+w) \sqrt{(A+1)^{2}+4 A w}} \\
& =1-\underbrace{\frac{w}{(1+R(w))(1+w)}}_{\in[0,1)}+\underbrace{\frac{w A}{R(w)(1+R(w))[1+w] \sqrt{(A+1)^{2}+4 A w}}}_{>0}>0 .
\end{aligned}
$$

Therefore, $s_{w}(w, R(w))>0$ for all $w \geq 0$.

To prove c) it suffices to show that the second total derivative of the saving function

$$
\begin{aligned}
& s_{w w}(w, R(w))= \\
& \quad 2 \frac{s(w, R(w)) s_{w}(w, R(w)) R_{w}(w)}{w R(w)^{2}}+\frac{s(w, R(w))^{2} R_{w w}(w)}{w R(w)^{2}}-2 \frac{s(w, R(w))^{2} R_{w}(w)^{2}}{w R(w)^{3}}
\end{aligned}
$$


is negative for all $w>0$. Since

$$
\begin{aligned}
R_{w w}(w) & =-\frac{2 R_{w}(w)}{1+w}-\frac{2 A^{2}}{(1+w)\left[\sqrt{(A+1)^{2}+4 A w}\right]^{3}} \\
& =-2 R_{w}(w)\left[\frac{1}{1+w}+\frac{A}{(A+1)^{2}+4 A w}\right]-\frac{2 A R(w)}{(1+w)\left[(A+1)^{2}+4 A w\right]}
\end{aligned}
$$

we obtain

$$
\begin{aligned}
& s_{w w}(w, R(w)) \\
& =2 \frac{s(w, R(w))}{w} s_{w}(w, R(w)) \frac{R_{w}(w)}{R(w)^{2}}-2 \frac{s(w, R(w))^{2}}{w} \frac{R_{w}(w)^{2}}{R(w)^{3}} \\
& -2\left[\frac{1}{1+w}+\frac{A}{(A-1)^{2}+4 A(1+w)}\right] \frac{s(w, R(w))^{2}}{w} \frac{R_{w}(w)}{R(w)^{2}} \\
& =2 \frac{s(w, R(w))^{2} R_{w}(w)}{w R(w)^{2}}\left[-\frac{2 A}{(1+w)\left[(A-1)^{2}+4 A(1+w)\right]} \frac{1}{w(w)}\right. \\
& \left.-\frac{1}{1+w}-\frac{A R(w)}{(A-1)^{2}+4 A(1+w)}+\frac{s_{w}(w, R(w))}{s(w, R(w))}-\frac{R_{w}(w)}{R(w)^{2}}\right]
\end{aligned}
$$

The fraction $\frac{s(w, R(w))^{2} R_{w}(w)}{w R(w)^{2}}$ is negative for all $w>0$, because $R_{w}(w)<0$ for all $w>0$. It remains to show that the sum of the terms in brackets, say $\Theta(w)$, is positive for all $w>0$. Using (24), (25), and (14) it follows that

$$
\begin{aligned}
\Theta(w)= & -\frac{A R(w)}{\left[A-R(w) \sqrt{(A+1)^{2}+4 A w}\right] \sqrt{(A+1)^{2}+4 A w}} \\
& -\frac{A}{(A+1)^{2}+4 A w}+\frac{1}{w}-\frac{1}{1+w}+\frac{R_{w}(w)}{(1+R(w)) R(w)}-\frac{R_{w}(w)}{R(w)} \\
= & \underbrace{\frac{1}{w(1+w)}}_{>0}-\underbrace{\frac{R_{w}(w)}{1+R(w)}-\underbrace{\frac{A^{2}}{(A+1)^{2}+4 A w}}_{>0}\left[A-R(w) \sqrt{(A+1)^{2}+4 A w}\right.}_{<0}]^{-1}
\end{aligned}
$$

Therefore, $\Theta(w)>0$ if $A-R(w) \sqrt{(A+1)^{2}+4 A w}<0$, which is equivalent to

$$
2 A(1+w)+(A-1)\left[A-1+\sqrt{(A+1)^{2}+4 A w}\right]>0 .
$$

This condition is fulfilled for all $w>0$, because Assumption 2.1 guarantees $A>1$.

Proof of Lemma 2.4: Property a) follows directly from Lemma 2.2.a). The inequality $h(1, z) \geq 1$ is fulfilled if $A z \beta \geq 1+(1+A z \beta) / A$ which is equivalent to $z \beta A^{2}-(1+z \beta) A-1 \geq 0$. Condition of $\mathrm{b}$ ) can be derived by solving this quadratic inequality. 
The partial derivative of $h$ with respect to $k$ is $h_{1}(k, z)=s_{w}(w(k, z), R(w(k, z))) w_{1}(k, z)$. Lemma 2.2.b) together with Lemma 2.3.b) implies that $h_{1}(0, z)=0$ and $h_{1}(k, z)>0$ for all $k>0$. Define $\kappa \equiv \log (1+k)-k /(1+k)$ and $H(z) \equiv A-1+\sqrt{(A-1)^{2}+4 A(1+A \kappa z)}$. Then the partial derivative of $h$ with respect to $z$ is

$$
h_{2}(k, z)=\frac{A \kappa\left[1+\frac{2(1+A \kappa z)}{H(z)}\right]-A \kappa z\left[\frac{2 A \kappa}{H(z)}-\frac{4 A^{2} \kappa^{2} z(1+A \kappa z)}{H(z)^{2} \sqrt{(A-1)^{2}+4 A(1+A \kappa z)}}\right]}{\left[1+\frac{2(1+A \kappa z)}{H(z)}\right]^{2}}
$$

which is positive if the numerator is positive. The numerator is equal to

$$
\frac{A \kappa H(z)+2 A \kappa}{H(z)}+\frac{4 A^{3} \kappa^{2} z^{2}(1+A \kappa z)}{H(z)^{2} \sqrt{(A-1)^{2}+4 A(1+A \kappa z)}},
$$

which is in fact positive, because so are $\kappa$ and $H(z)$. The second partial derivative of $h$ with respect to $k$ is

$$
h_{11}(k, z)=s_{w w}(w(k, z), R(w(k, z))) w_{1}(k, z)^{2}+s_{w}(w(k, z), R(w(k, z))) w_{11}(k, z) .
$$

Lemmas 2.3.b) and 2.3.c) imply that the first total derivative of the saving function $s$ with respect to $w$ is positive for positive wage income, whereas its second total derivative is negative for all $w(k, z)>0$. Furthermore, Lemma 2.2.b) and 2.2.c) yield that $w_{1}(k, z)>0$ for all $k>0$ and $w_{11}(k, z)<0$ for all $k \geq 1$, which completes the proof of property $\mathrm{c}$ ).

Proof of Lemma 2.5: Since the right-hand side of (20) is decreasing in $\underline{z}$, Lemma 2.4.b) implies that $h(1, z) \geq 1$ for all $z \in[\underline{z}, \bar{z}]$. The same Lemma yields that $k \mapsto h(k, z)$ is strictly concave for all $k \geq 1$. One further has that

$$
h(k, z) \leq s_{w}(0, R(0)) w(k, z) \leq A z \log (1+k)
$$

because Lemma 2.3.b) ensures $s_{w}(0, R(0))<1$. Hence for all sufficiently large $k \geq 1, h(k, z) \leq$ $k$. Therefore, strict concavity implies existence of a maximal fixed point $k(z) \geq 1 . k(z)$ is increasing by Lemma 2.4.c).

Proof of Theorem 3.1: Zero is a fixed point by Lemma 2.4.a), and Lemma 2.4.c) yields asymptotic stability of zero. Further, Lemma 2.4.c) ensures that $h(k, z)$ is increasing in $z$ and therefore $k_{t+1} \leq h\left(k_{t}, \bar{z}\right)$. Recalling that $h(k, \bar{z})<k$ in a neighborhood of zero, we obtain assertion (i).

The proof of existence of a random fixed point with the claimed properties is completely analogous to that of Theorem 4.2. in Schenk-Hoppé \& Schmalfuß (1998). We only have to check that $[k(\underline{z}), \infty$ [ is forward-invariant and that $k \mapsto h(k, z)$ is strictly concave for all $k \geq k(\underline{z})$. The latter is a direct consequence of Lemma 2.4.d). Lemmas 2.5 and 2.4.c) ensure existence of a capital stock $k(\underline{z}) \geq 1$ such that $h(k, z) \geq k(\underline{z})$ for all $k \geq k(\underline{z})$ and all $z \geq \underline{z}$. Thus the set $[k(\underline{z}), \infty[$ is mapped into itself under $h(\cdot, z(\omega))$.

Proof of Corollary 3.2: It suffices to check that there exists a proper interval $\mathcal{Z} \equiv[\underline{z}, \bar{z}]$ with $1 \in \operatorname{int} \mathcal{Z}$ such that conditions (20) and (23) hold for an arbitrary i.i.d. process with values in $\mathcal{Z}$. 
Observe that

$$
\mathbb{E} \log h_{1}(k(\underline{z}), z(\omega)) \leq \log \max _{z \in \mathcal{Z}} h_{1}(k(\underline{z}), \underline{z})
$$

where $k(z)$ is the maximal fixed point of the map $k \mapsto h(k, z)$. Further $\max _{z \in \mathcal{Z}} h_{1}(k(\underline{z}), z)=$ $h_{1}(k(1), 1)<1$ for $\underline{z}=\bar{z}=1$.

The result follows from continuity of $h_{1}(\cdot, \cdot)$, and $k(\cdot)$, and from continuity in $\underline{z}$ of the righthand side of $(20)$.

\section{References}

Arnold, L. (1998): Random Dynamical Systems. Springer-Verlag, New York.

Cooley, T. F. (ed.) (1995): Frontiers of Business Cycle Research. Princeton University Press, Princeton, NJ.

Danthine, J. P. \& J. B. Donaldson (1993): "Methodological and Empirical Issues in Real Business Cycles Theory", European Economic Journal, 37, 1-35.

Diamond, P. (1965): "National Debt in a Neoclassical Growth Model", American Economic Review, 55(5), 1126-1150.

Fehr, E. \& J.-R. Tyran (1998): "Does Money Illusion Matter? An Experimental Approach", Working Paper 9802, Department of Economics, University of St. Gallen, available at http://www.iew.unizh.ch/grp/fehr/wp-fehr.html.

Frisch, R. (1933): "Propagation Problems and Impulse Problems in Dynamic Economics", in Economic Essays. In Honor of Gustav Cassel. Allen \& Unwin, London.

Grandmont, J.-M. (1977): “Temporary General Equilibrium Theory", Econometrica, 45(3), $535-572$.

Hansen, G. D. (1985): "Indivisible Labor and the Business Cycle", Journal of Monetary Economics, 16, 309-327.

Karni, E. (1993a): "A Definition of Subjective Probabilities with State-Dependent Preferences", Econometrica, 61(1), 187-198.

(1993b): "Subjective Expected Utility with State-Dependent Preferences", Journal of Economic Theory, 60(2), 428-438.

King, R. G., C. I. Plosser \& S. T. Rebelo (1988): "Production, Growth and Business Cycles - I. The Basic Neoclassical Model", Journal of Monetary Economics, 21, 195-232.

Kydland, F. E. \& E. C. Prescott (1990): "Business Cycles: Real Facts and a Monetary Myth", Federal Reserve Bank of Minneapolis Quarterly Review, 14(2), 3-18.

Marimon, R. \& A. Scott (eds.) (1999): Computational Methods for the Study of Dynamic Economies. Oxford University Press, Oxford a.o. 
Mas-Colell, A., M. D. Whinston \& J. R. Green (1995): Microeconomic Theory. Oxford University Press, Oxford a.o.

McCallum, B. T. (1989): "Real Business Cycle Models", in Modern Business Cycle Theory, ed. by R. J. Barro, chap. 1, pp. 16-50. Basil Blackwell, Oxford a.o.

Prescott, E. (1986): "Theory Ahead of Business Cycle Measurement", Federal Reserve Bank of Minneapolis Quarterly Review, 10(4), 9-22.

SchenK-Hoppé, K. R. (1999): "MATlab scripts for the simulation of an OLG model with stochastic production", web page http://www.iew.unizh.ch/home/klaus/numerics/, Institute for Empirical Research in Economics, University of Zurich.

Schenk-Hoppé, K. R. \& B. Schmalfuss (1998): "Random Fixed Points in a Stochastic Solow Growth Model", Discussion Paper 387, Department of Economics, University of Bielefeld, submitted.

Schmalfuss, B. (1996): "A Random Fixed Point Theorem Based on Lyapunov Exponents", Random \& Computational Dynamics, 4, 257-268.

- (1998): "A Random Fixed Point Theorem and the Random Graph Transformation", Journal of Mathematical Analysis and Applications, 225, 91-113.

Shafir, E., P. Diamond \& A. Tversky (1997): "On Money Illusion”, Quarterly Journal of Economics, 112, 341-374.

Spear, S. E. \& S. Srivastava (1986): "Markov Rational Expectations Equilibria in an Overlapping Generations Model", Journal of Economic Theory, 38, 35-62.

Taylor, J. B. \& H. Uhlig (1990): "Solving Nonlinear Stochastic Growth Models: A Comparison of Alternative Solution Models", Journal of Business and Economic Statistics, 8(1), 1-18.

WANG, Y. (1993): "Stationary Equilibria in an Overlapping Generations Economy with Stochastic Production", Journal of Economic Theory, 61, 423-435.

(1994): "Stationary Markov Equilibria in an OLG Model with Correlated Production Shocks", International Economic Review, 35(4), 731-744. 


\section{Working Papers of the Institute for Empirical Research in Economics}

No.

1. Rudolf Winter-Ebmer and Josef Zweimüller: Firm Size Wage Differentials in Switzerland: Evidence from Job Changers, February 1999

2. Bruno S. Frey and Marcel Kucher: History as Reflected in Capital Markets: The Case of World War II, February 1999

3. Josef Falkinger, Ernst Fehr, Simon Gächter and Rudolf Winter-Ebmer: A Simple Mechanism for the Efficient Provision of Public Goods - Experimental Evidence, February 1999

4. Ernst Fehr and Klaus M. Schmidt: A Theory of Fairness, Competition and Cooperation, April 1999

5. Markus Knell: Social Comparisons, Inequality, and Growth, April 1999

6. Armin Falk and Urs Fischbacher: A Theory of Reciprocity, April 1999

7. Bruno S. Frey and Lorenz Goette: Does Pay Motivate Volunteers?, May 1999

8. Rudolf Winter-Ebmer and Josef Zweimüller: Intra-firm Wage Dispersion and Firm Performance, May 1999

9. Josef Zweimüller: Schumpeterian Entrepreneurs Meet Engel's Law: The Impact of Inequality on InnovationDriven Growth, May 1999

10. Ernst Fehr and Simon Gächter: Cooperation and Punishment in Public Goods Experiments, June 1999

11. Rudolf Winter-Ebmer and Josef Zweimüller: Do Immigrants Displace Young Native Workers: The Austrian Experience, June 1999

12. Ernst Fehr and Jean-Robert Tyran: Does Money Illusion Matter?, June 1999

13. Stefan Felder and Reto Schleiniger: Environmental Tax Reform: Efficiency and Political Feasibility, July 1999

14. Bruno S. Frey: Art Fakes - What Fakes?, An Economic View, July 1999

15. Bruno S. Frey and Alois Stutzer: Happiness, Economy and Institutions, July 1999

16. Urs Fischbacher, Simon Gächter and Ernst Fehr: Anomalous Behavior in Public Goods Experiments: How Much and Why?: Comment, August 1999

17. Armin Falk, Ernst Fehr and Urs Fischbacher: On the Nature of Fair Behavior, August 1999

18. Vital Anderhub, Simon Gächter and Manfred Königstein: Efficient Contracting and Fair Play in a Simple Principal-Agent Experiment, August 1999

19. Simon Gächter and Armin Falk: Reputation or Reciprocity?, September 1999

20. Ernst Fehr and Klaus M. Schmidt: Fairness, Incentives, and Contractual Choices, September 1999

21. Urs Fischbacher: z-Tree - Experimenter's Manual, September 1999

22. Bruno S. Frey and Alois Stutzer: Maximising Happiness?, October 1999

23. Alois Stutzer: Demokratieindizes für die Kantone der Schweiz, October 1999

24. Bruno S. Frey: Was bewirkt die Volkswirtschaftslehre?, October 1999

25. Bruno S. Frey, Marcel Kucher and Alois Stutzer: Outcome, Process \& Power in Direct Democracy, November 1999

26. Bruno S. Frey and Reto Jegen: Motivation Crowding Theory: A Survey of Empirical Evidence, November 1999

27. Margit Osterloh and Bruno S. Frey: Motivation, Knowledge Transfer, and Organizational Forms, November 1999

28. Bruno S. Frey and Marcel Kucher: Managerial Power and Compensation, December 1999

29. Reto Schleiniger: Ecological Tax Reform with Exemptions for the Export Sector in a two Sector two Factor Model, December 1999

30. Jens-Ulrich Peter and Klaus Reiner Schenk-Hoppé: Business Cycle Phenomena in Overlapping Generations Economies with Stochastic Production, December 1999

The Working Papers of the Institute for Empirical Research in Economics can be downloaded in PDF-format from http://www.unizh.ch/iew/wp/

Institute for Empirical Research in Economics, Blümlisalpstr. 10, 8006 Zürich, Switzerland

Phone: 004116343705 Fax: 004116344907 E-mail: bibiewzh@iew.unizh.ch 